Article

\title{
High-Performance Sustainable Asphalt Mixtures for High-Volume Traffic Roads in Severe Climates
}

\author{
Fernando Moreno-Navarro ${ }^{1, *}$, Francisco Javier Sierra ${ }^{2}$, Miguel Sol-Sánchez ${ }^{1}$, \\ M. Carmen Rubio-Gámez ${ }^{1}$ D, Manuel Castillo $^{3}$ and Eugenio Estévez ${ }^{3}$ \\ 1 Laboratory of Construction Engineering (LabIC.UGR), School of Civil Engineering (ETSICCP), \\ University of Granada, Dr. Severo Ochoa s/n, 18071 Granada, Spain; msol@ugr.es (M.S.-S.); \\ mcrubio@ugr.es (M.C.R.-G.) \\ 2 Consejería de Fomento y Vivienda de la Junta de Andalucía, Avd. Joaquina Eguaras, 2, 18071 Granada, \\ Spain; franciscoj.sierra@juntadeandalucia.es \\ 3 Construcciones Pérez Jiménez, Avda. Andalucía s/n, 18015 Granada, Spain; mcastillo@grpj.com (M.C.); \\ eestevez@grpj.com (E.E.) \\ * Correspondence: fmoreno@ugr.es
}

Received: 15 September 2020; Accepted: 19 October 2020; Published: 22 October 2020

\begin{abstract}
This paper summarizes the work carried out in a research project whose main objective was to develop high-performance sustainable bituminous materials (using crumb rubber and additives to reduce their manufacturing temperature) to be used in roads that support high traffic volumes and/or severe environmental conditions. For this purpose, various studies were conducted both in a laboratory and in a real asphalt plant (at binder and mixture level). Later, these materials were used to construct a trial section in a highway at a mountain pass (at more than $1400 \mathrm{~m}$ above sea level) supporting more than 2600 heavy vehicles each day under severe environmental conditions (snow during winter, and high temperatures and many hours of solar radiation during the summer). The results indicate the viability of using these materials, since they provide a number of advantages such as improved workability at lower temperatures and an increase in the mechanical resistance against the main sources of distress that affect asphalt pavements.
\end{abstract}

Keywords: asphalt; crumb rubber; warm mix asphalt; sustainability; bituminous mixtures

\section{Introduction}

The economic and social developments of recent decades have led to the need for more efficient and sustainable road infrastructures. In this regard, efforts have been focused on developing more durable materials that allow for increasing the service life of road pavements (by, for instance, optimizing economic investment while minimizing the social impact by reducing traffic interruption and pollution) [1]. Similarly, more sustainable products and construction processes are being developed to minimize the consumption of raw materials and energy while reducing the pollution that is generated during construction, maintenance, or renewal activities. Thus, one of the current challenges in the road pavement industry concerns the implementation of a circular economy in which materials are reused whilst applying more environmentally friendly construction techniques [2-4].

Given these current challenges, the use of crumb rubber as a binder modifier is becoming an increasingly widespread solution due to the environmental benefits of reducing the accumulation of this waste material, along with the fact that this modifier appears to provide the binder with a higher viscosity than conventional polymers (such as SBS and EVA) [5]. This allows for the use of higher dosages of bitumen during the manufacturing of asphalt mixtures, which in turn results in greater resistance to cracking [6,7], whilst also reducing permanent deformations, binder aging, and susceptibility to in-service temperature fluctuations $[8,9]$. 
However, despite these benefits, an increase in binder viscosity limits the workability of the asphalt mixtures (since they require a higher manufacturing temperature and more compaction energy whilst being more susceptible to lower temperatures during pavement construction) [10]. All of this implies a greater risk when applying these materials in cold climates or in situations that involve long transport distances. Thus, applying mixtures with crumb rubber could be limited under these circumstances, while negative economic and environmental impacts can also be seen in other cases due to the need for a higher manufacturing temperature.

In order to address this issue, a joint research project carried out by the Ministry of Public Works and Housing of Andalucía (Junta de Andalucía), the construction company Pérez Jiménez, and the Laboratory of Construction Engineering of the University of Granada, has focused on developing a high-performance sustainable asphalt mixture manufactured with crumb rubber from end-of-use tires at a low temperature (by using additives to obtain warm mix asphalts) [11-13]. The aim of this project was to obtain a material that could be used as an overlay in the rehabilitation of a road subjected to a high volume of traffic and/or severe climate conditions. This paper presents the main findings from the laboratory phase of developing this mixture (binder and mixture level), its production in-plant, and its application in the rehabilitation of a pavement section in the A-92 Highway (in the province of Granada, Spain).

\section{Methodology}

\subsection{Materials}

Given the need to obtain a high-performance and sustainable asphalt mixture (for the rehabilitation of deteriorated road pavements to improve safety and comfort), the type of mixture selected for this study was a BBTM 11 [14]. This material has a high air void content $(12-18 \%)$ and is commonly used as a surface layer with a thickness of around $3-4 \mathrm{~cm}$, providing a significant reduction in noise while increasing vehicle-road adherence and reducing water splash.

For the design of this mixture, limestone aggregates were used for the fine fraction $(0 / 6 \mathrm{~mm})$, ophitic aggregates for the coarse fraction $(4 / 12 \mathrm{~mm})$, and cement as a filler (all these materials have appropriate characteristics for the manufacturing of asphalt mixtures according to the Spanish Standard PG-3 [15]). For the binders, two types of high-performance bitumens were used: a crumb rubber (CR)-modified bitumen (referred to in this article as CRMB) and a SBS polymer-modified bitumen (referred to as PMB) used as a reference to evaluate the effect of crumb rubber. The main characteristics of aggregates and binders used for the manufacture of the asphalt mixtures are summarized in Tables 1 and 2.

Using these materials, two different hot mix asphalt BBTM 11 were designed: CRMB-HMA and PMB-HMA (manufactured at $175^{\circ} \mathrm{C}$ with the same mineral skeleton and binder content, but using $\mathrm{CRMB}$ and $\mathrm{PMB}$, respectively). Additionally, a third asphalt mixture was developed using the same mineral skeleton and the $C R M B$, but its manufacturing temperature was reduced to obtain warm-mix asphalt (CRMB-WMA). For this purpose, a chemical additive was used during the manufacturing of the CRMB-WMA (which modifies the surface of the aggregate on an alkyl surface that is more compatible with the asphalt binder and improves manufacturing, paving, and compacting processes). The mineral skeleton was composed of $76 \%$ of $4 / 12 \mathrm{~mm}$ ophitic coarse aggregates, $20 \%$ of $0 / 6 \mathrm{~mm}$ limestone sand, and $4 \%$ of Portland cement filler (Figure 1). 
Table 1. Characteristics of the aggregates used in the manufacture of the asphalt mixtures.

\begin{tabular}{|c|c|c|c|}
\hline & & $\begin{array}{c}\text { Coarse Aggregate } \\
(4 / 12 \mathrm{~mm}) \\
\text { Ophite }\end{array}$ & $\begin{array}{c}\text { Fine Aggregate } \\
(0 / 6 \mathrm{~mm}) \\
\text { Limestone }\end{array}$ \\
\hline \multirow{7}{*}{$\begin{array}{l}\text { Particle granulometry, } \\
\text { (UNE-EN 933-1) }\end{array}$} & Sieve & $\begin{array}{l}\% \text { of material } \\
\text { passing }\end{array}$ & $\begin{array}{l}\% \text { of material } \\
\text { passing }\end{array}$ \\
\hline & 11.2 & 96.5 & 100 \\
\hline & 8 & 47.5 & 100 \\
\hline & 4 & 7.5 & 82.2 \\
\hline & 2 & 0.4 & 73.9 \\
\hline & 0.5 & 0.3 & 31.9 \\
\hline & 0.063 & 0.3 & 2.5 \\
\hline \multicolumn{2}{|c|}{ Sand equivalent, (UNE-EN 933-8) } & - & 81 \\
\hline \multicolumn{2}{|c|}{ Percent of fractured face (UNE-EN 933-5) } & $100 \%$ & - \\
\hline \multicolumn{2}{|c|}{ Flakiness index, (UNE-EN 933-3) } & 20 & - \\
\hline \multicolumn{2}{|c|}{ Resistance to fragmentation (UNE-EN1097-2) } & 14 & - \\
\hline \multicolumn{2}{|c|}{ Resistance to polishing (UNE 146130 annex D) } & 0.51 & - \\
\hline \multicolumn{2}{|c|}{ Cleaning of coarse aggregate (UNE 146130 annex C) } & $0.02 \%$ & - \\
\hline \multirow{2}{*}{$\begin{array}{l}\text { Relative density and } \\
\text { absorption (EN 1097-6) }\end{array}$} & Apparent relative density & $2.85 \mathrm{~g} / \mathrm{cm}^{3}$ & $2.80 \mathrm{~g} / \mathrm{cm}^{3}$ \\
\hline & Absorption coefficient & $1.57 \%$ & $0.77 \%$ \\
\hline
\end{tabular}

Table 2. Characteristics of the binders used in the manufacture of the asphalt mixtures.

\begin{tabular}{ccc}
\hline Characteristics & CRMB & PMB \\
\hline Penetration at $25^{\circ} \mathrm{C}(\mathrm{dmm})$, EN 1426 [16] & $45-80$ & $45-80$ \\
\hline Softening point $\left({ }^{\circ} \mathrm{C}\right)$, EN 1427 [17] & $>60$ & $>60$ \\
\hline Elastic Recovery at $25^{\circ} \mathrm{C}(\%)$, EN 13398 [18] & $>70$ & $>70$ \\
\hline
\end{tabular}

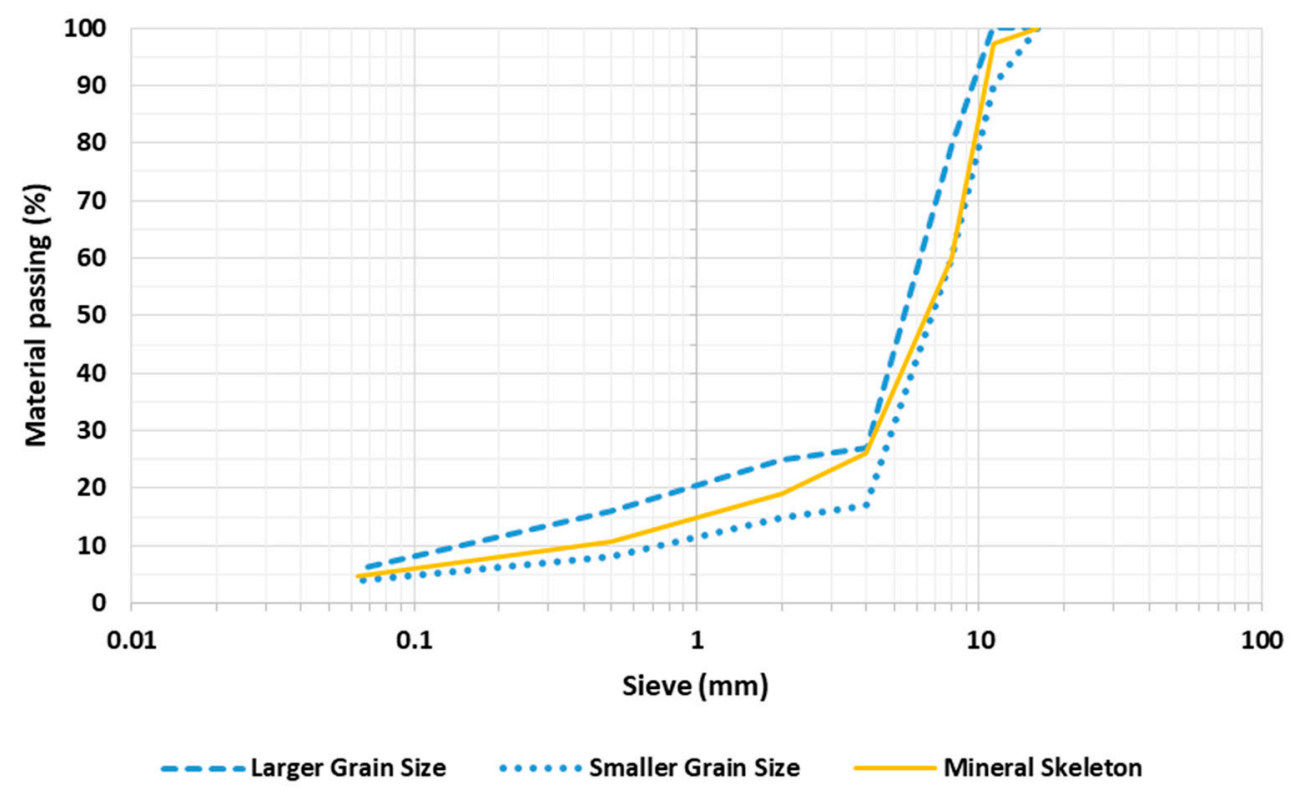

Figure 1. Mineral skeleton of the BBTM 11 mixture used in the study. 


\subsection{Testing Plan}

The testing plan followed in this study was divided into three main stages: (i) laboratory study (assessment of binders and design of the asphalt mixtures); (ii) analysis of mixture reproducibility in-plant; (iii) application of the mixture in a trail section.

The first stage, conducted in the laboratory, consisted of evaluating the characteristics of both types of binders as well as the properties of the designed mixtures. To assess the rheological behavior of the CRMB in comparison with the traditional PMB, complex modulus and phase angle were measured at different temperatures $\left(10,20,30,40,45,52,58,64,70\right.$, and $80^{\circ} \mathrm{C}$, in order to perform a precise analysis of the rheological response of the two binders under severe thermal gradients) and a range of frequencies (from $0.1 \mathrm{~Hz}$ to $20 \mathrm{~Hz}$ ), using a Dynamic Shear Rheometer (DSR) through a shear loading at a constant amplitude of $0.1 \%$ strain (using two specimens per binder). Similarly, this equipment was used to carry out the MSCRT (Multiple Stress Creep and Recovery Test) to evaluate the resistance of the binders to permanent deformations, along with their ability to recover the elastic strain under different levels of stress ( 0.1 and $3.2 \mathrm{kPa}$, applying loading cycles consisting of 1 second loads and a 9-second recovery phase) at various temperatures $\left(45,65\right.$, and $\left.70^{\circ} \mathrm{C}\right)$ and using two specimens per binder.

Regarding the design of the PMB-HMA and CRMB-HMA hot mixtures, the water sensitivity test [19], wheel tracking test [20], bulk density test [21], and air void content test [22] were conducted to determine optimal binder content. The water sensitivity test involves the manufacture of 6 test specimens with a diameter of $101.6 \mathrm{~mm}$ and a thickness of $60 \mathrm{~mm}$, compacted with 50 blows on each side by a Marshall hammer. The specimens were subsequently divided into two sets of three specimens (a dry set and a wet set). The dry set was stored at room temperature in the laboratory $\left(20 \pm 5^{\circ} \mathrm{C}\right)$, whereas a vacuum was applied to the wet set for $30 \pm 5 \mathrm{~min}$ until a pressure of $6.7 \pm 0.3 \mathrm{kPa}$ was obtained. The specimens were then immersed in water at a temperature of $40{ }^{\circ} \mathrm{C}$ over a period of 72 hours. The next step was to perform an indirect traction resistance test on each of the cylinders (in both the dry set and the wet set). This was done at a temperature of $15^{\circ} \mathrm{C}$, and after a previous period of adjustment of $120 \mathrm{~min}$ to this temperature. The results of the experiment are expressed in terms of the retained strength of the test specimens after dividing the strengths of the wet specimens into the strengths of the dry specimens (ITSR, \%).

The wheel tracking test involves the manufacture of two prismatic test specimens of $408 \mathrm{~mm} \times 256 \mathrm{~mm}$. Compaction was carried out by a roller compactor with a smooth steel roller to a thickness of $60 \mathrm{~mm}$ and a minimum density of $98 \%$ of the Marshall density. Two days after their compaction, both specimens were allowed to adjust to a temperature of $60 \pm 1{ }^{\circ} \mathrm{C}$, and then were tested at that temperature. The test itself involved the application of a load on the test specimen by means of the repeated passes of a loaded wheel. The load applied was $700 \mathrm{~N}$ and the number of passes was 10,000 . The frequency of the device was 26.5 load cycles per minute. In each of the wheel passes, the resulting deformation on the test cylinder was measured. The objective of the test was to determine the wheel tracking slope (WTS, $\mathrm{mm} / 10^{3}$ load cycles) measured in the last 5000 load cycles.

Following this, and using the same design as that used for the CRMB-HMA, the workability of the CRMB-WMA at lower manufacturing temperatures $\left(150^{\circ} \mathrm{C}\right.$ and $\left.130^{\circ} \mathrm{C}\right)$ was assessed in comparison with the conventional RMB-HMA (which was manufactured at $175^{\circ} \mathrm{C}$ ). For this purpose, the density of the mixtures as a function of the compaction energy at different temperatures was analyzed (using a gyratory compactor), while evaluating the stiffness modulus at $20^{\circ} \mathrm{C}[23]$ and loss of particles at $25^{\circ} \mathrm{C}$ [24] of the specimens obtained following the compaction process. Additionally, having selected the most appropriate manufacturing temperature of the RMB-WMA, its properties and mechanical performance were compared with the conventional hot mixtures PMB-HMA and RMB-HMA using the same tests described previously (water sensitivity, wheel-tracking, bulk density, and air void content).

Stiffness modulus was measured using the Indirect Tensile Stiffness Modulus Test (ITSM) as described in standard UNE-EN 12697-26 (Annex C). For the performance of the complete test, three test cylinders were manufactured for each of the mixtures studied. These specimens with a diameter of $101.6 \mathrm{~mm}$ and heights ranging from $35 \mathrm{~mm}$ to $75 \mathrm{~mm}$ were compacted with 50 blows on each side by a 
Marshall hammer. This test determined the stiffness modulus, based on a series of 15 load pulses with controlled strain and sinusoidal waveform of a three-second duration. The first ten pulses conditioned the equipment so that it could adjust to the size of the load and its duration. Values were obtained within the limits established by the standard (which establishes that the value of the test load factor should be between 0.5 and 0.7 , the deformation value should neither be greater than $20 \mu \mathrm{m}$ nor less than $3 \mu \mathrm{m}$, and the rise time should be 120-128 ms). The five subsequent pulses determined the stiffness modulus of the mix, which was the mean value of the five pulses. Once this value was calculated, the cylinder was turned to determine the modulus along the perpendicular diameter. This modulus should be $80-110 \%$ of the first value otherwise the test is not valid. The final value of the stiffness modulus of each specimen is the mean value of both diameters. The stiffness modulus of each mix is the mean value of the results obtained for the three test cylinders.

In the second study stage, following the design and evaluation of the mixtures at a laboratory level, a series of mixing processes were carried out in a real asphalt plant for each type of mixture (PMB-HMA, CRMB-HMA, and CRMB-WMA) to test their reproducibility. For this purpose, after their manufacture in-plant, the samples were taken to evaluate their mechanical response in the laboratory using the water sensitivity test [19] and wheel-tracking test [20]. Additionally, to assess their performance under severe climatic actions, the particle loss test [24] was also carried out under the following conditions: the response to water action was tested by comparing the results at $25^{\circ} \mathrm{C}$ after conditioning in hot water at $60^{\circ} \mathrm{C}$ for 24 hours in comparison with those obtained when tested in dry conditions at $25^{\circ} \mathrm{C}$; the effect of temperature was tested by conducting the test at 10,25 , and $60^{\circ} \mathrm{C}$; and the effect of aging was tested after conditioning at $165^{\circ} \mathrm{C}$ for 12 hours. Furthermore, the bearing capacity of the mixtures manufactured in-plant was assessed through the stiffness test [19] at 5 , 20, and $40^{\circ} \mathrm{C}$; cracking resistance was assessed at low temperatures using the TSRST (Thermal Stress Restrained Specimen Test, [25]) and fatigue cracking was evaluated using the UGR-FACT (University of Granada Fatigue Asphalt Concrete Test) at 10, 20, and $30^{\circ} \mathrm{C}[26,27]$.

In the third phase of the study, the mixtures were used in the rehabilitation of a section of pavement on the A-92 highway (in the province of Granada, Spain). The location of the trial section was selected according to environmental and technical criteria. Regarding the first of these criteria, the section was placed in a mountain pass in a natural park where the use of CRMB-WMA (manufactured with recycled materials and at low temperatures) would help to reduce the negative impacts caused by road construction (in addition, the type of mixture used could reduce noise levels due to traffic rolling). Regarding the second criterion, the mixtures were evaluated under extreme conditions on account of the high volume of traffic (more than 18,000 vehicles per day, with a daily average of more than 2600 heavy vehicles) and extreme climate conditions (the section was placed at more than $1400 \mathrm{~m}$ above sea level, with the presence of snow during winter, and high temperatures and many hours of solar radiation during summer) (Figure 2). In addition, this section was ideal for evaluating the real workability of the CRMB-WMA mixture since the transit time from plant to worksite was approximately 1 hour (Figure 3 ). The temperatures of the asphalt pavement operations were in a range between 12 and $28^{\circ} \mathrm{C}$.

Finally, to complete the assessment of the performance of the CRMB-WMA in reference to the conventional high-performance mixtures (RMB-HMA and PMB-HMA), a series of cores were obtained from the pavements to evaluate their bulk density [21] following compaction of the sections, whilst the stiffness test [23] and UGR-FACT (at $20^{\circ} \mathrm{C}$ ) were also carried out to evaluate their mechanical response. 

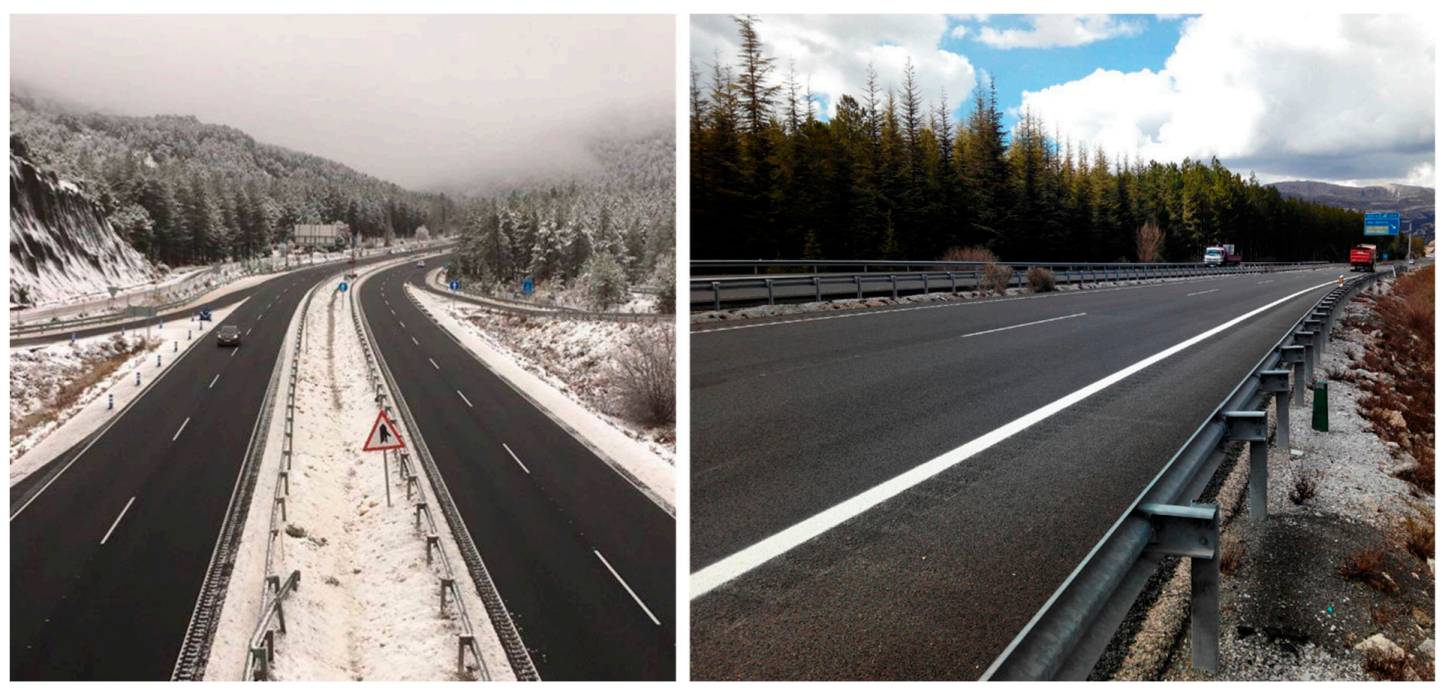

Figure 2. View of the A-92 Highway, in winter (left) and summer (right) periods.

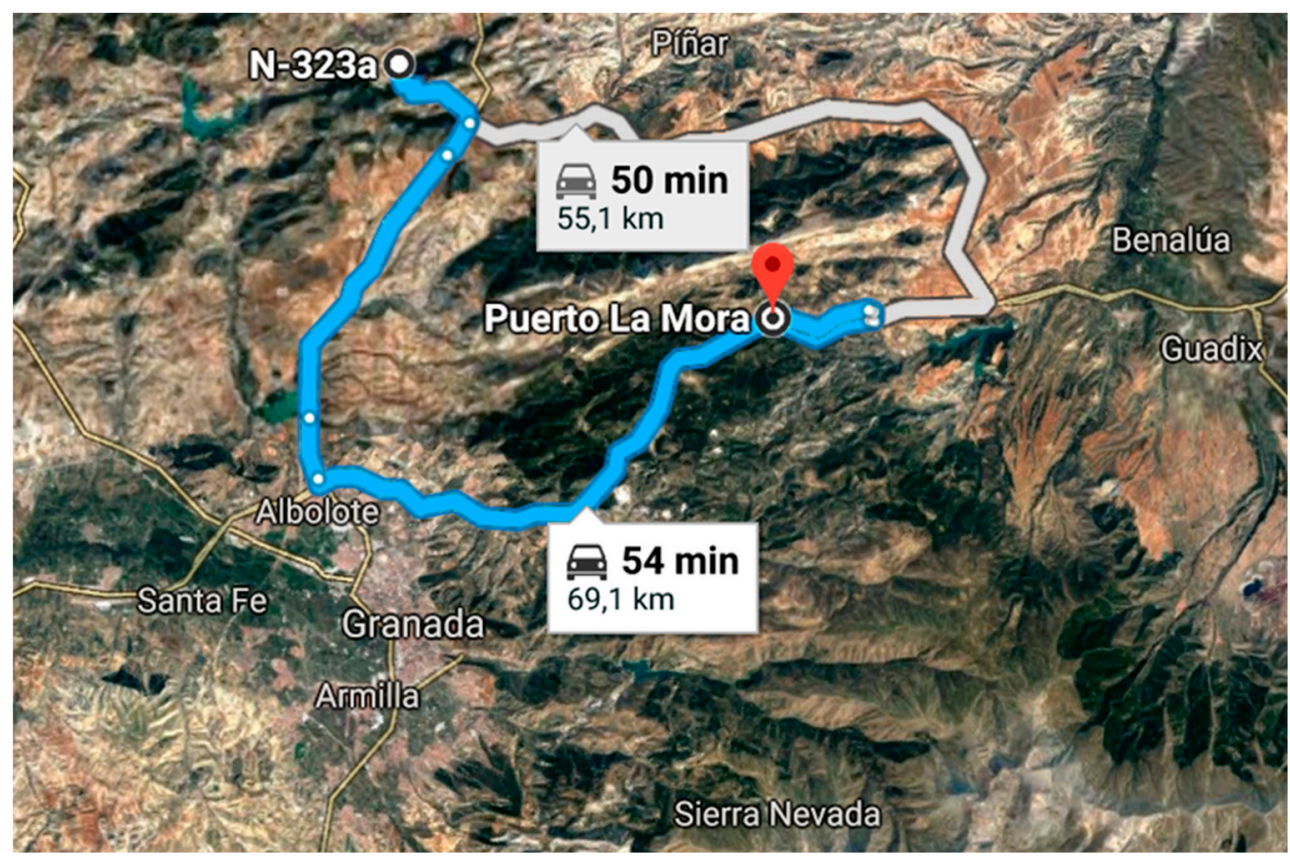

Figure 3. Distance from plant to the place of rehabilitation of the pavement (Source: Google Maps).

\section{Analysis of the Results}

\subsection{Laboratory Study}

Figures 4 and 5 show the results obtained in the rheological study for the PMB and CRMB. In particular, Figure 4a shows the changes in the response of the binders through the Black diagrams (complex modulus and phase angle) depending on the test temperature and frequency, while Figure $4 \mathrm{~b}$ displays the isochrones of the complex modulus and phase angle as a function of the temperature at a constant frequency of $5 \mathrm{~Hz}$. Figure 5 shows the results of the MSCRT through the elastic recovery and the permanent deformations with the Jnr parameter at $3.2 \mathrm{kPa}$.

Figure 4a shows the thermorheologically complex response (noted by the non-superposition of the curves at high temperatures) of the studied binders (due to the presence of the polymers). In these diagrams, higher phase angles and lower complex modulus are related to more viscous/flexible materials (or tested at higher temperatures), while lower phase angles and higher complex modulus 
are related to more elastic/rigid materials (or tested at lower temperatures). In this respect, both binders presented quite similar visco-elastic behavior. Nonetheless, it is seen that the CRMB led to a slightly more elastic performance, particularly at high temperatures where it presents a lower phase angle. This can also be observed in Figure $4 \mathrm{~b}$ where both binders recorded similar isochrones, decreasing the complex modulus and increasing phase angle with an increase in the test temperature, but obtaining a slightly lower phase angle of CRMB at high temperatures in comparison with conventional PMB.
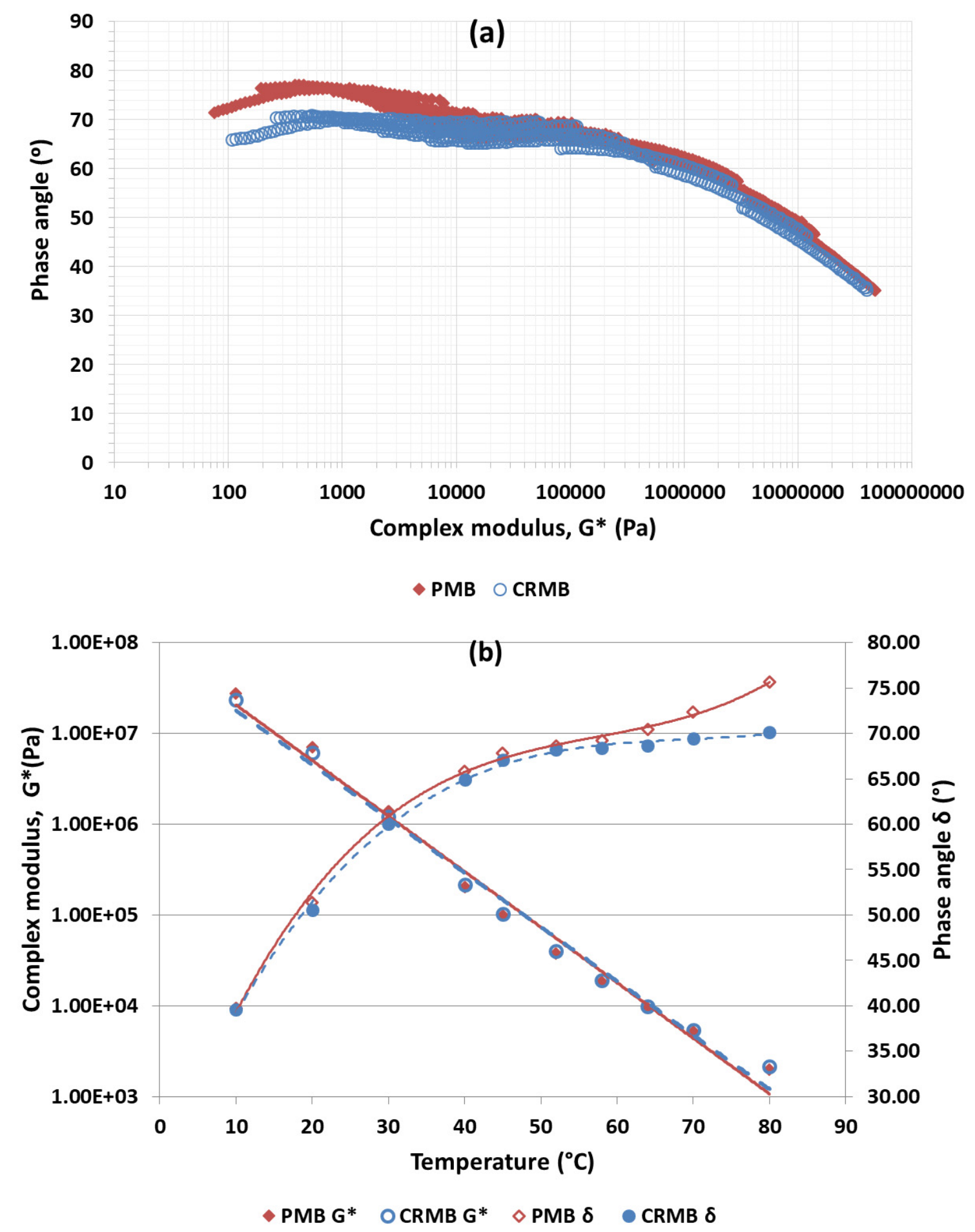

Figure 4. Results from the rheological study for the RMB and PMB: (a) Black diagram; (b) Isochrones at $5 \mathrm{~Hz}$. 


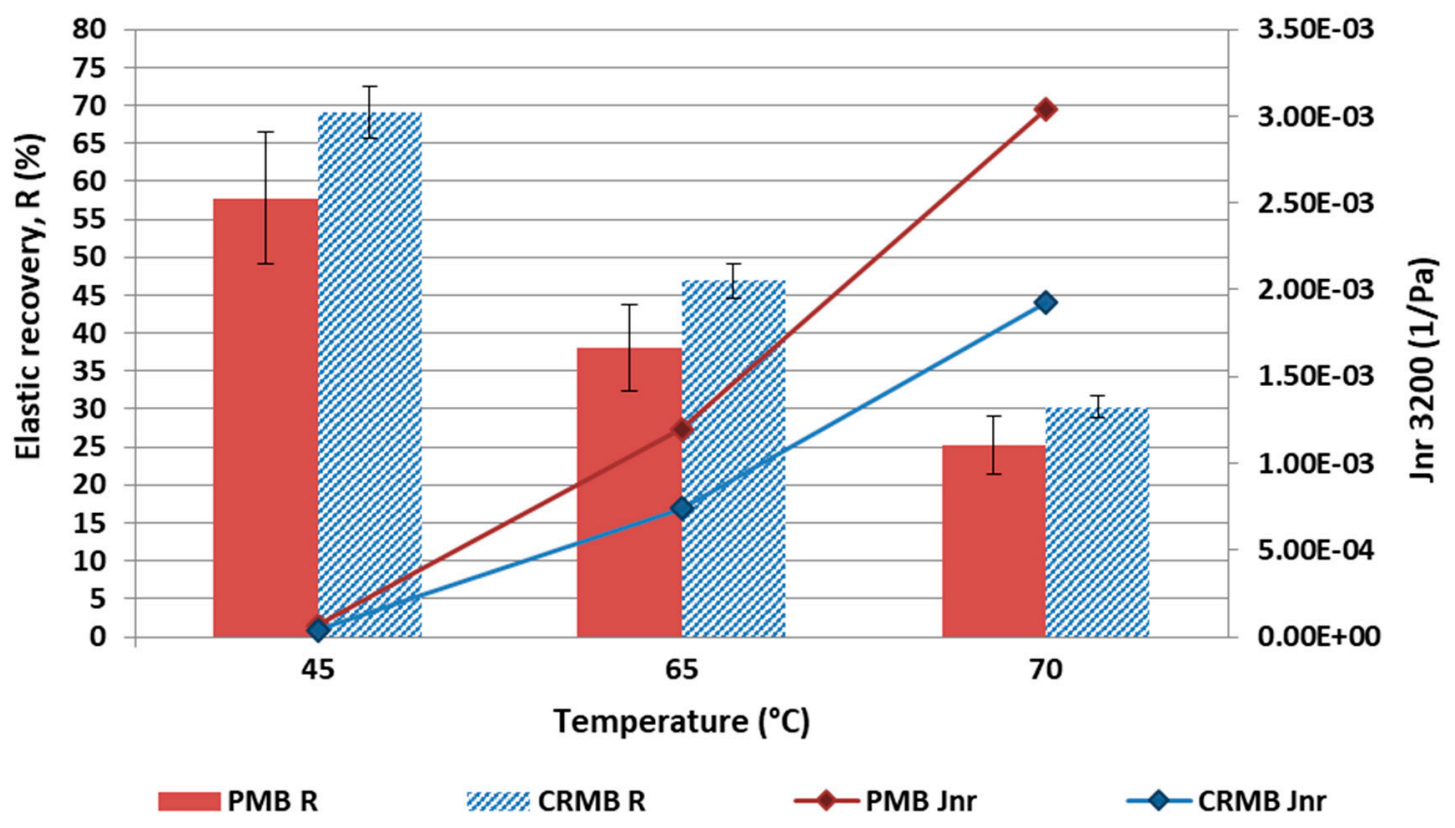

Figure 5. Results of the MSCRT at different temperatures.

In Figure 5, it is seen that the CRMB (with a quantity of crumb rubber around $15 \%$ over the total weight of binder) offered higher elastic recovery and higher resistance to permanent deformations (around $40 \%$ lower Jnr values), regardless of the test temperature. These results are in consonance with those obtained on the frequency sweep tests. These results, therefore, indicate that the CRMB presented similar (or even superior) mechanical performance to conventional PMB, which makes it appropriate for its application in the manufacturing of the high-performance mixtures.

Once the bitumens had been evaluated, the design of the bituminous mixtures was carried out. Table 3 lists the main properties obtained during the design tests carried out for the hot mixtures (PMB-HMA and CRMB-HMA) when selecting the optimal binder content (which was the same in both cases, i.e., $4.75 \%$ over the total weight of the mixture).

Table 3. Main characteristics of the mixtures designed in the laboratory.

\begin{tabular}{cccc}
\hline Characteristics & PMB-HMA & CRMB-HMA CRMB-WMA \\
\hline Bulk density $\left(\mathrm{Mg} / \mathrm{m}^{3}\right), \mathrm{EN} 12697-6$ & 2.146 & 2.134 & 2.137 \\
\hline Air voids $(\%), \mathrm{EN} 12697-8$ & 16.5 & 18.0 & 17.9 \\
\hline Indirect tensile strength at $15^{\circ} \mathrm{C}(\mathrm{kPa}), \mathrm{EN} 12697-23$ & 1287 & 1161 & 1182 \\
\hline ITSR $(\%), \mathrm{EN} 12697-12$ & 91.9 & 90.7 & 94.0 \\
\hline $\mathrm{WTS}$ at $60^{\circ} \mathrm{C}\left(\mathrm{mm} / 10^{3}\right.$ ciclos), EN 12697-22 & 0.056 & 0.054 & 0.068 \\
\hline
\end{tabular}

Based on the design of the CRMB-HMA, the design of the CRMB-WMA manufactured at a lower temperature was carried out (using the same binder content of $4.75 \%$ over the total weight of the mixture). Figure 6 presents the results obtained from studying the workability of the CRMB-WMA manufactured at $130^{\circ} \mathrm{C}$ and $150^{\circ} \mathrm{C}$ in reference to the conventional CRMB-HMA manufactured at $175^{\circ} \mathrm{C}$. The results confirmed that the decrease in manufacturing and compaction temperature (CRMB-WMA 150 and $130^{\circ} \mathrm{C}$ ) led to a significant reduction in density in comparison with the hot mixture used for reference. Nonetheless, the mixtures manufactured with the additive (CRMB-WMA) appeared to offer a lower reduction in density when using manufacturing temperatures of approximately $150{ }^{\circ} \mathrm{C}$ (with workability much more similar to that offered by the hot mixture). Similarly, Figure 7 shows that a decrease in manufacturing and compaction temperature led to a significant reduction in the 
mechanical performance of the mixtures (measured through stiffness modulus and particle loss). Nonetheless, it was again observed that using the additive allows for performance that is comparable to the conventional CRMB-HMA at $175^{\circ} \mathrm{C}$ when the CRMB-WMA is manufactured at a temperature of around $150{ }^{\circ} \mathrm{C}$. In particular, similar particle loss was observed despite recording lower stiffness (almost $45 \%$ less), which could be related to the lower oxidation of the binder during the manufacture of the CRMB-WMA.

Therefore, based on the previous results, it appears that the CRMB-WMA could be manufactured at temperatures of around $150{ }^{\circ} \mathrm{C}$ when using the chemical additive. In this respect, Table 3 demonstrates that the job mix formula of the CRMB-WMA manufactured at this temperature presented quite a similar density to the traditional high-performance mixtures as well as comparable tensile strength, susceptibility to water action (as measured by the ITSR-Indirect Tensile Strength Ratio), and resistance to permanent deformations (WTS parameter - Wheel Tracking Slope). This indicates that the CRMB-WMA manufactured at around $150^{\circ} \mathrm{C}$ can be used in the construction or rehabilitation of road pavements.

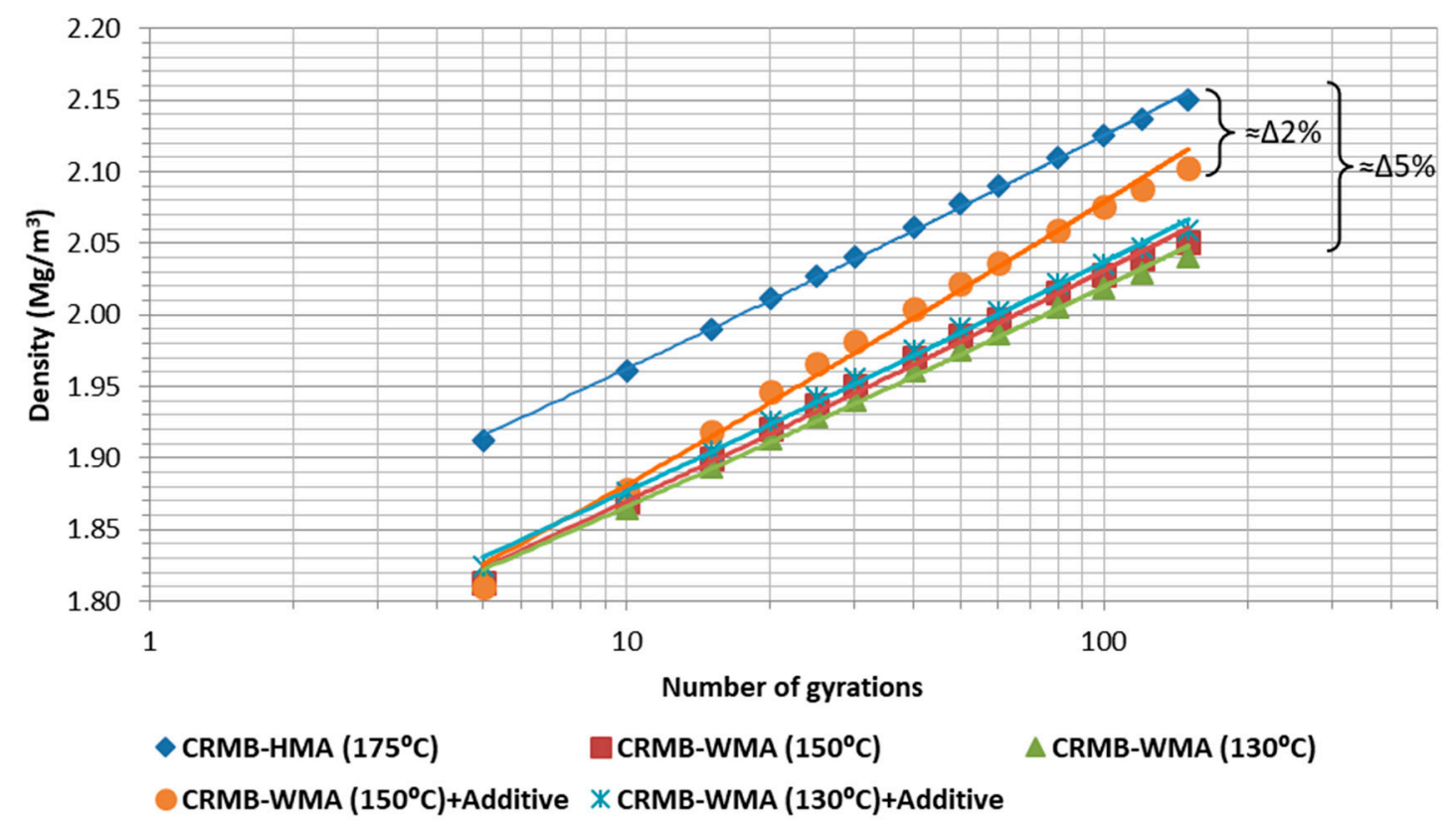

Figure 6. Curves of density versus energy of compaction at different temperatures. 

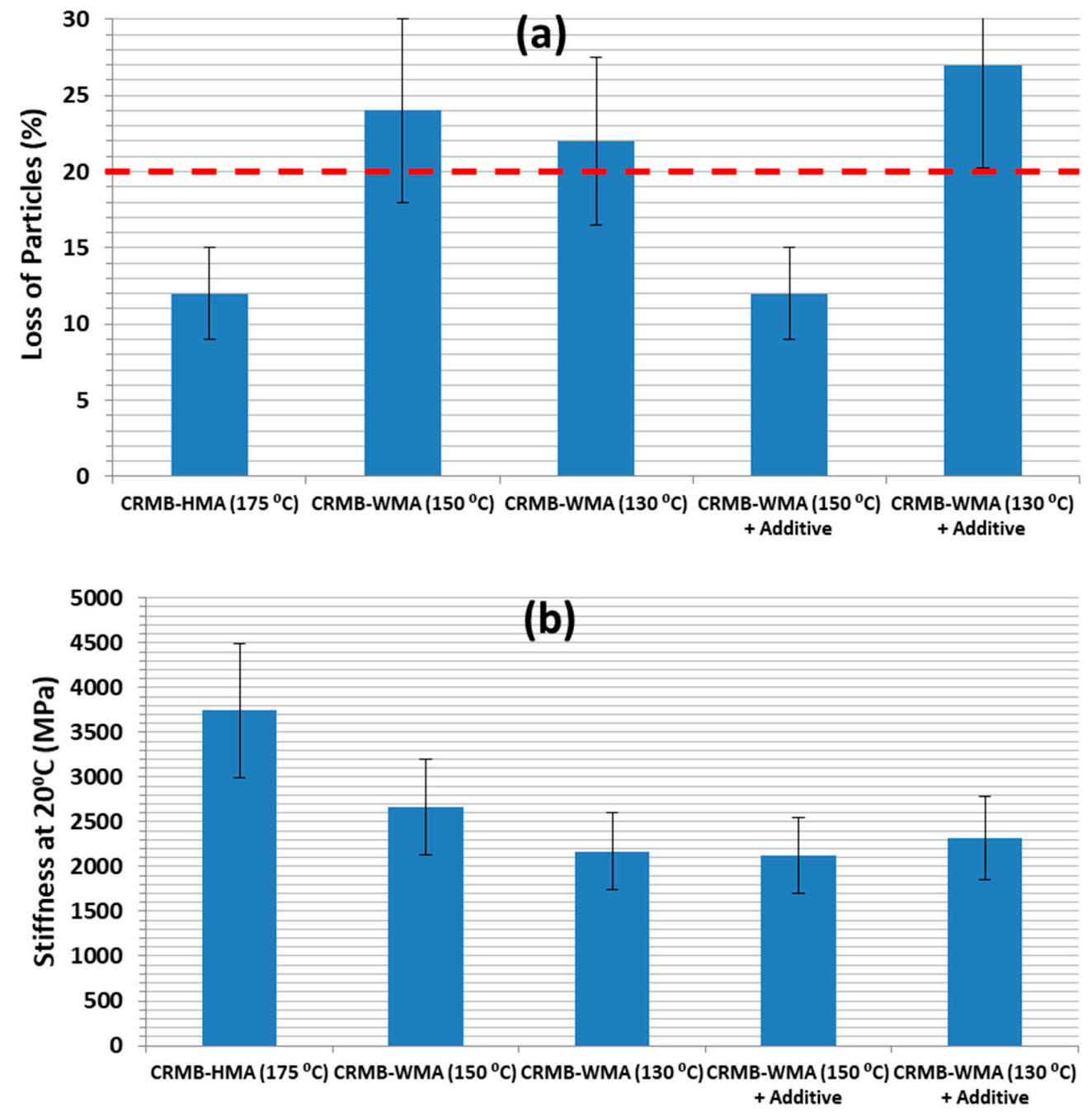

Figure 7. Results of the mechanical response of the RMB mixtures: (a) particle loss; (b) stiffness at $20^{\circ} \mathrm{C}$.

\subsection{Reproducibility of Mixtures in a Real Plant}

After designing the mixtures in the laboratory, these were manufactured in-plant to analyze the reproducibility of the job mix formulas. In this case, and based on the results obtained in the previous stage, the manufacturing temperature used for the CRMB-WMA was set at $145^{\circ} \mathrm{C}$. Table 4 lists the data related to the consumption and production measured during the manufacture of the mixtures (CRMB-HMA and CRMB-WMA). Reducing the manufacturing temperature of the CRMB-WMA mixture led to an approximate $20-30 \%$ reduction in fuel consumption in-plant, which could partially compensate for the cost overrun associated with the use of the additive (the final extra cost estimated for the CRMB-WMA was lower than $0.6-0.7 \%$ in reference to the conventional HMA).

Table 4. Data from the production in-plant of the mixtures manufactured with the CRMB.

\begin{tabular}{ccc}
\hline Characteristics & CRMB-HMA & CRMB-WMA \\
\hline Aggregates temperature $\left({ }^{\circ} \mathrm{C}\right)$ & $172-178$ & $146-148$ \\
\hline Flame of the drum dryer $(\%)$ & $72-81$ & $37-59$ \\
\hline Fuel consumption $(\mathrm{kg} / \mathrm{tn})$ & $6.8-7.2$ & $5.4-5.9$ \\
\hline
\end{tabular}

Table 5 shows the results of the water sensitivity and wheel tracking tests obtained for each type of material collected from the mixtures manufactured in the asphalt plant. It is proven that the 
reproducibility of the CRMB-WMA in-plant was adequate, again presenting comparable results to those measured for the conventional hot mixtures with both types of high-performance bitumens (PMB-HMA and CRMB-HMA), while obtaining similar results to those obtained in the laboratory study.

Table 5. Results of the water sensitivity test and wheel-tracking tests for the mixtures manufactured in-plant.

\begin{tabular}{cccc}
\hline Characteristics & PMB-HMA & RMB-HMA & RMB-WMA \\
\hline Indirect tensile strength at $15^{\circ} \mathrm{C}(\mathrm{kPa}), \mathrm{EN} \mathrm{12697-23}$ & 1111 & 1040 & 1108 \\
\hline $\mathrm{ITSR}(\%), \mathrm{EN} 12697-12$ & 90.5 & 90.9 & 90.1 \\
\hline WTS at $60^{\circ} \mathrm{C}\left(\mathrm{mm} / 10^{3}\right.$ ciclos), EN 12697-22 & 0.048 & 0.066 & 0.056 \\
\hline
\end{tabular}

Figures 8 and 9 display the results obtained in the study of cohesion of the mixtures through the measures of particle loss under various climatic actions (water, temperature, and aging). The results show that lowering the test temperature led to a significant increase in particle loss due to the more brittle behavior of the bitumen, obtaining a ratio of increase of around $0.2 \% /{ }^{\circ} \mathrm{C}$ between $25-60{ }^{\circ} \mathrm{C}$, and $4.5 \% /{ }^{\circ} \mathrm{C}$ between $10-25^{\circ} \mathrm{C}$. Nonetheless, a slight decrease in particle loss could be obtained when using the CRMB for both cases, the HMA and WMA present similar behavior despite the decrease in manufacturing temperature in the case of the WMA.

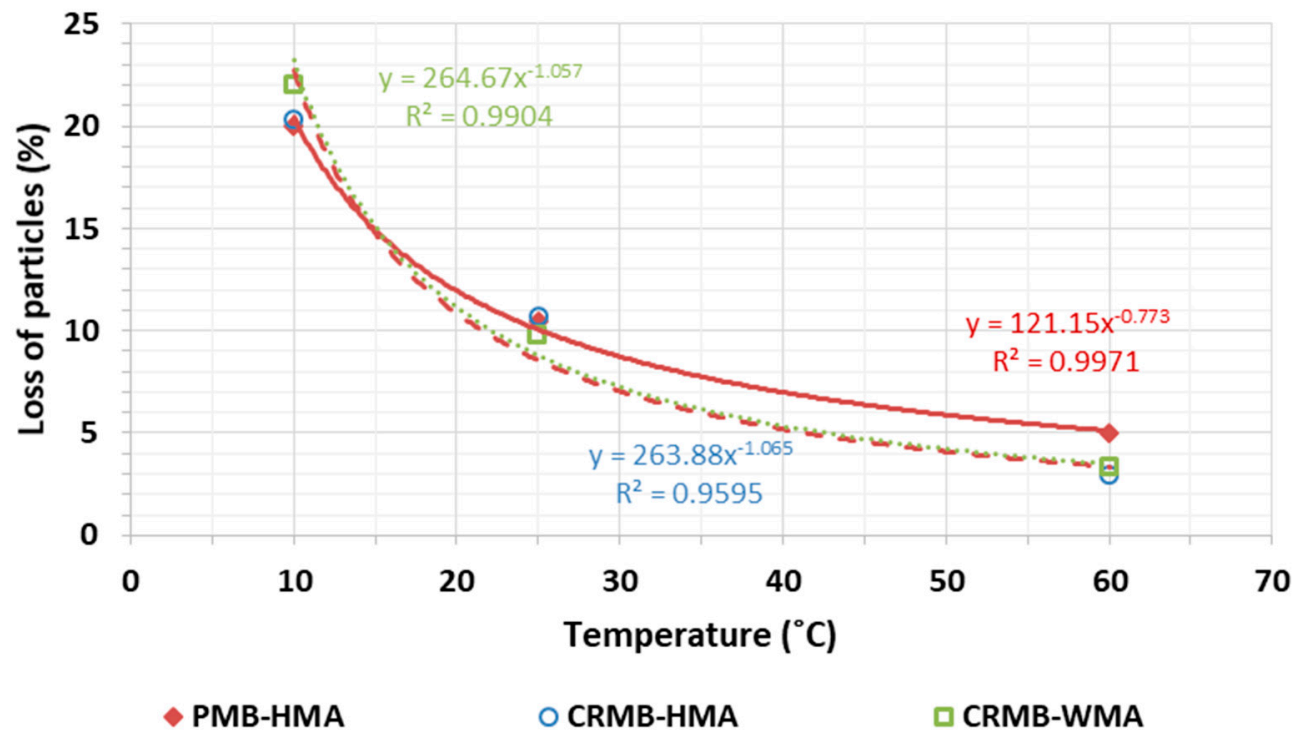

Figure 8. Results of particle loss at different temperatures.

Similarly, Figure 8 indicates that the WMA mixture showed similar susceptibility to the increase in particle loss due to the action of water (around 5-7\%, Figure 9a) or the effect of aging (between 1-9\%, Figure 9b). Therefore, lowering the production temperature of the CRMB mixture allowed the material to show a similar mechanical performance to the traditional HMA (even under adverse climate actions) when using the chemical additive with a manufacturing temperature of approximately $145^{\circ} \mathrm{C}$.

Figure 10 displays the results of the stiffness modulus of the various mixtures under different testing temperatures $\left(5,20\right.$, and $\left.40^{\circ} \mathrm{C}\right)$. Again it appears that the mechanical behavior of the CRMB-WMA was similar to that shown for the CRMB-HMA, and both present values close to those measured for the mixture produced with the traditional polymer-modified binder (PMB-HMA).

To analyze the resistance to cracking of the mixtures, Figure 11 displays the results of TSRST (which measures the development of the force acting on the specimen when decreasing the temperature up to material failure) while Figure 12 shows the results of UGR-FACT through the number of cycles to failure at different testing temperatures (Figure 12a) and the values of Mean Parameter 
Damage (Figure 12b) [28]. The results show that the three asphalt mixtures presented a comparable performance in terms of resistance to cracking. Nonetheless, it can be seen that, in general, the mixtures manufactured with CRMB showed slightly superior performance to that of the traditional PMB-HMA, regardless of the manufacturing temperature of the CRMB mixtures (showing higher resistance to cracking and lower temperature to failure; a slight increase in the number of cycles needed to produce fatigue cracking, and less damage in the specimen).

25

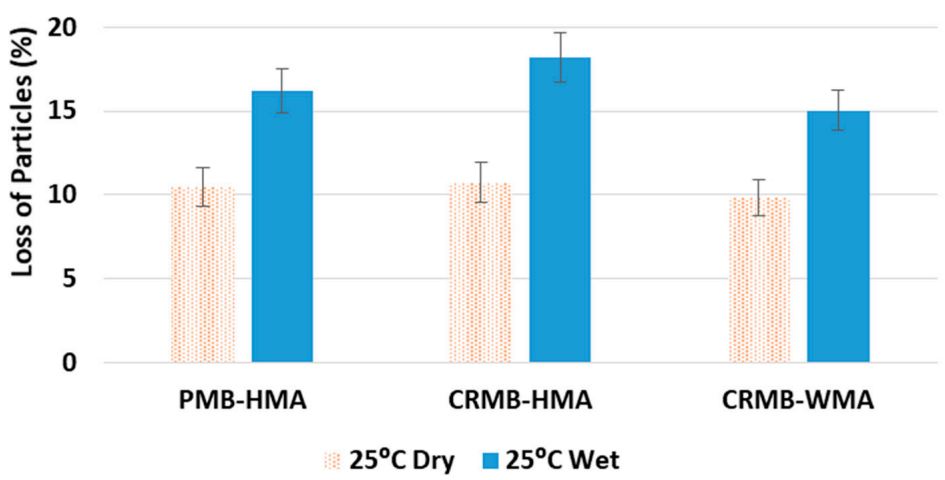

25

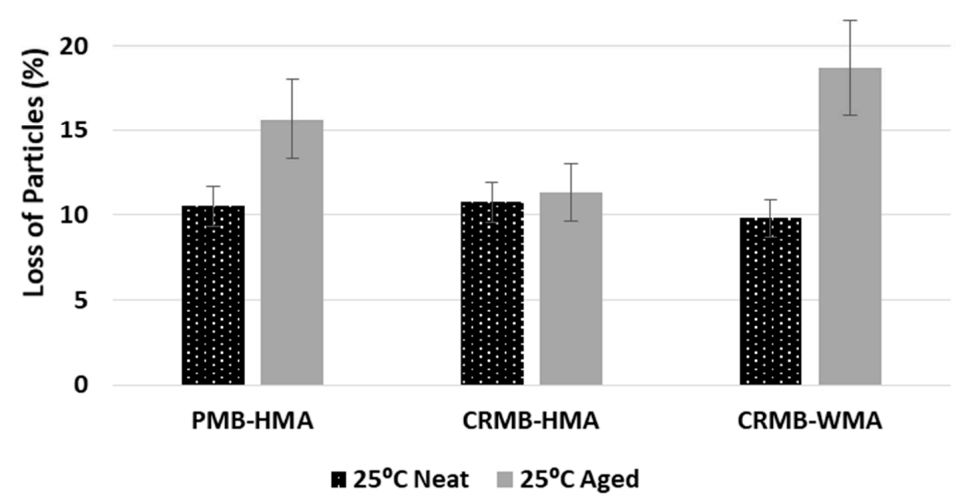

Figure 9. Particle loss for the mixtures following (a) water action and (b) aging simulation.

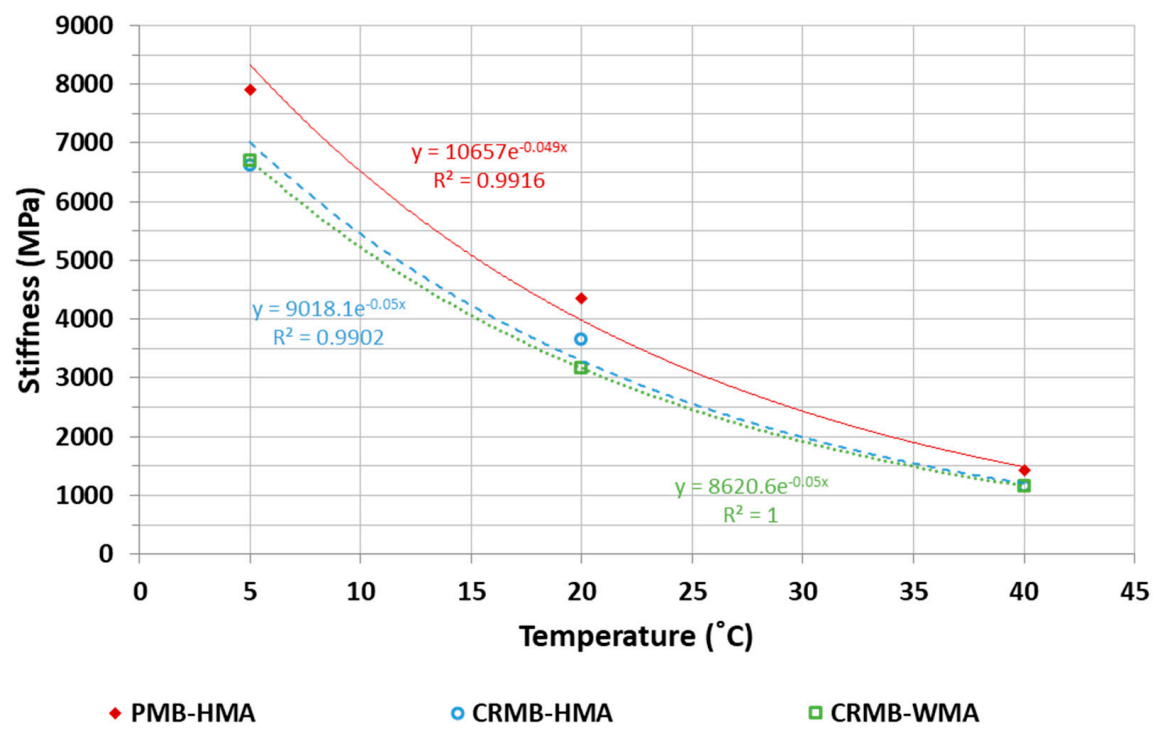

Figure 10. Stiffness modulus at different testing temperatures for the mixtures from the plant. 


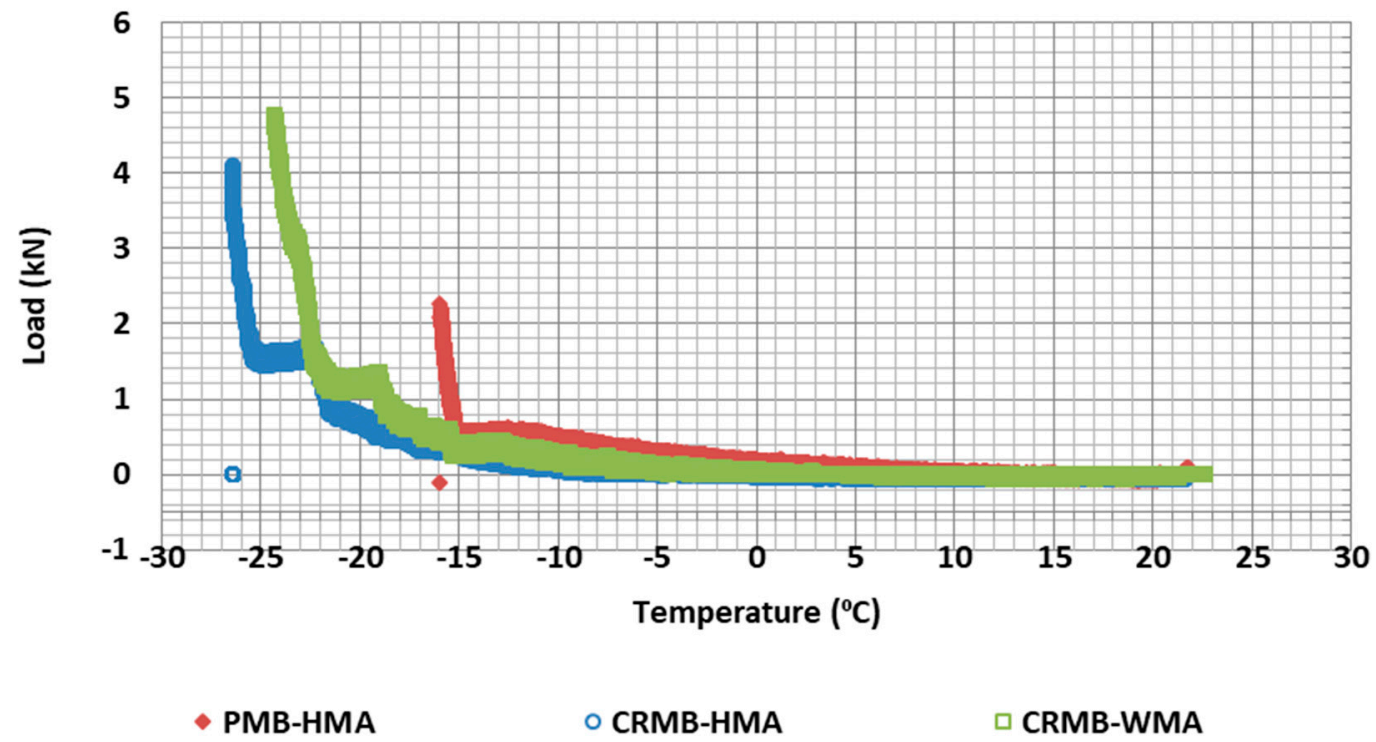

Figure 11. Results of TSRST for the different mixtures.
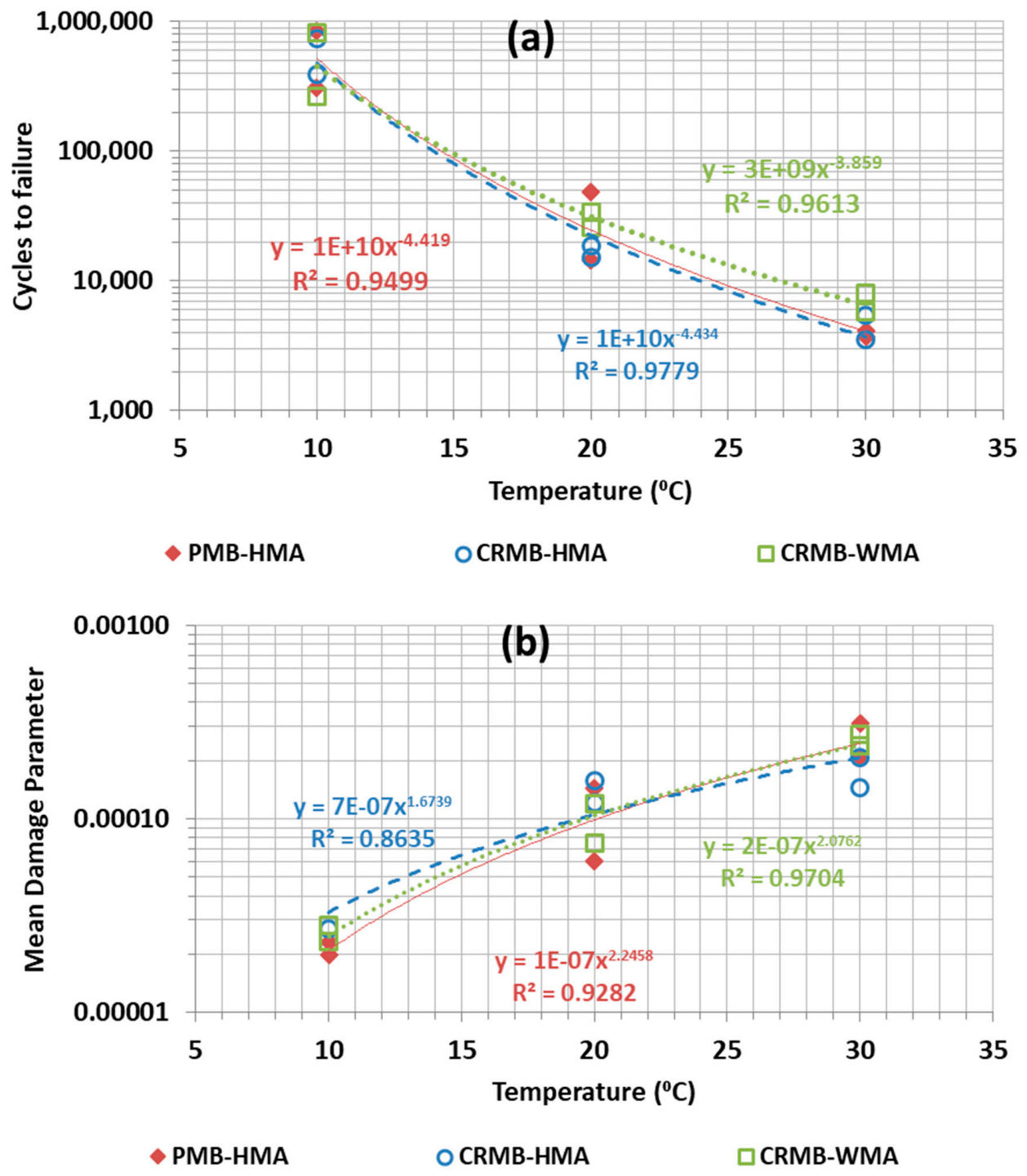

Figure 12. Results of UGR-FACT: (a) number of cycles to failure; (b) Mean Damage Parameter. 


\subsection{Trial Section}

After demonstrating the adequate performance of the CRMB-WMA manufactured in the asphalt plant, the trial sections were constructed by using the equipment and machinery routinely employed with traditional mixtures. Figures 13-15 show that while few differences were observed in the visual aspect of the CRMB-WMA in reference to the CRMB-HMA or the PMB-HMA, there was a significant decrease in the temperature of the material following the spreading and compaction works (Figure 13 shows the aspect of the CRMB-WMA during spreading and after compaction).

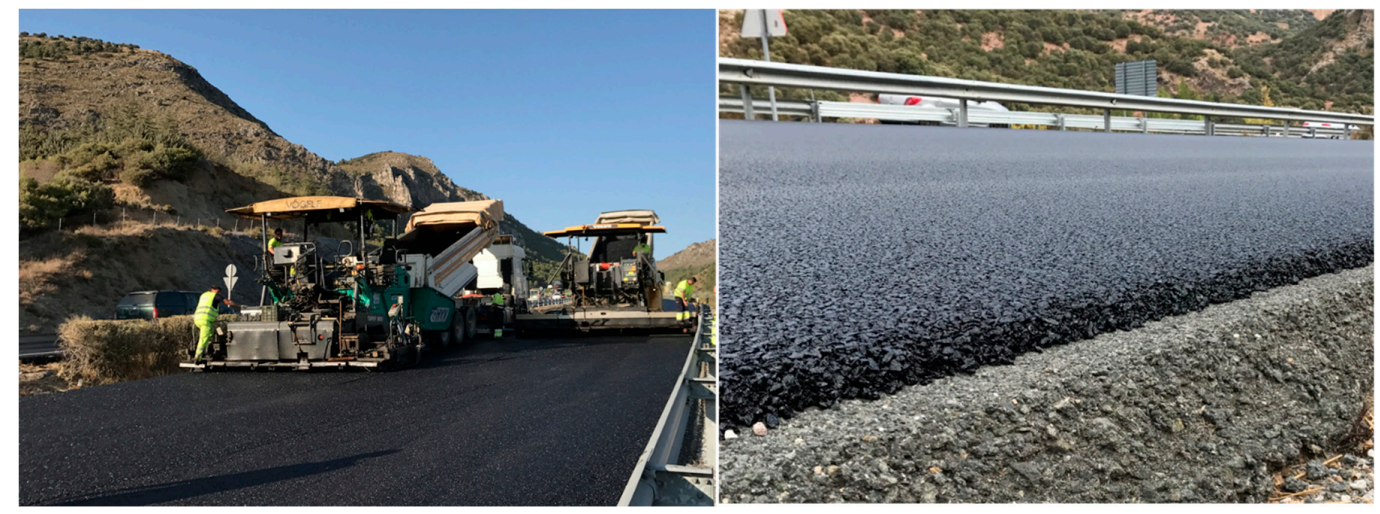

Figure 13. Images from the spreading and compaction of the CRMB-WMA with a thickness of $3 \mathrm{~cm}$.
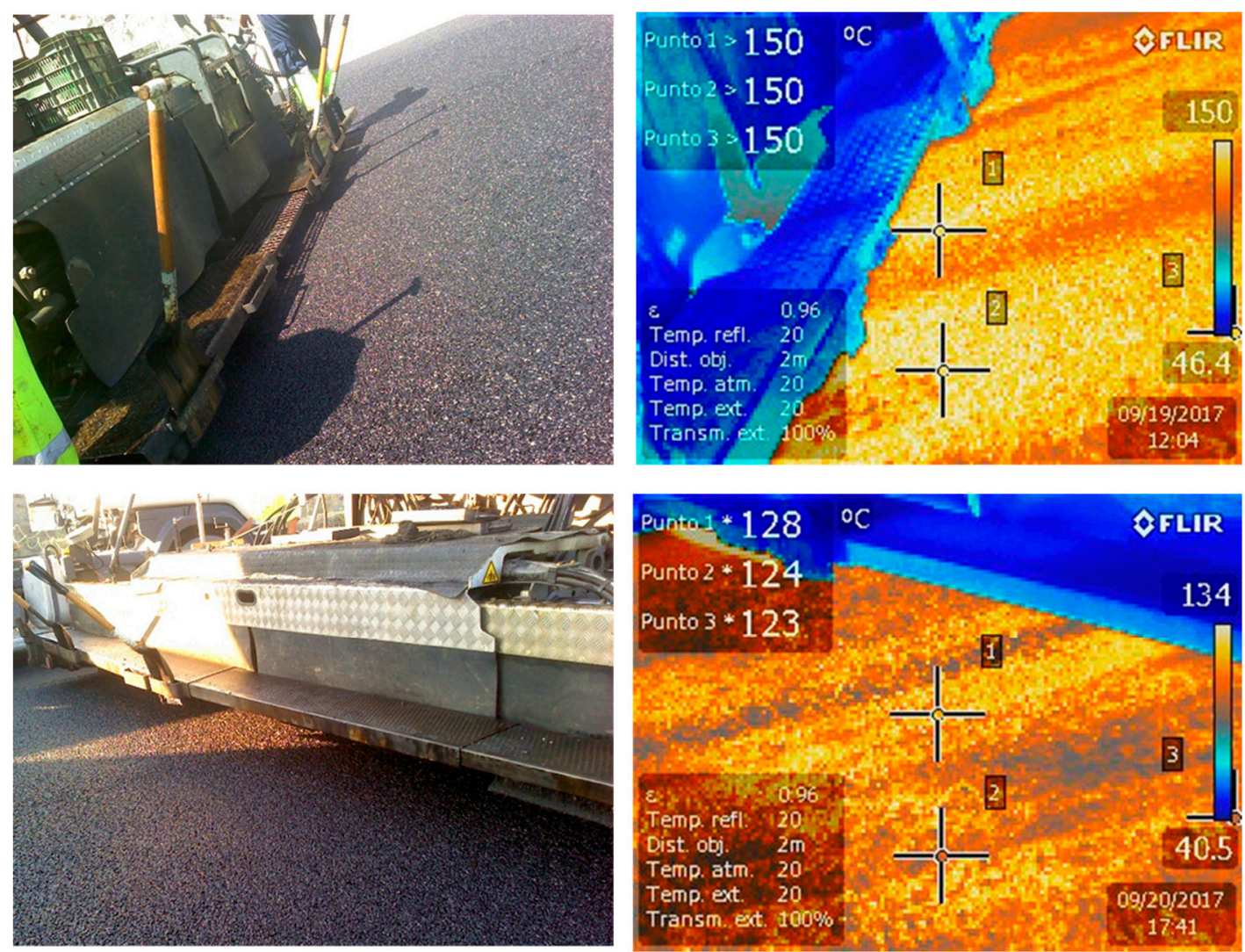

Figure 14. Comparison of the spreading temperature for the conventional CRMB-HMA (top) and the CRMB-WMA (bottom). 

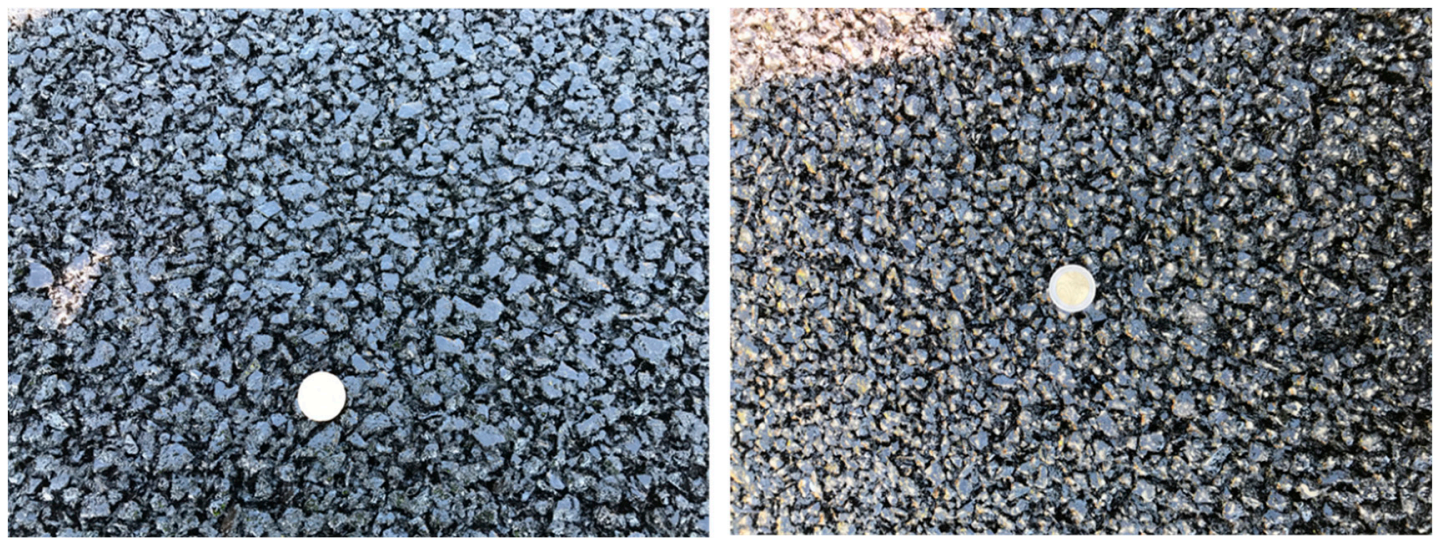

Figure 15. Visual appearance of the CRMB-HMA (left) and CRMB-WMA (right) after compaction.

For the cores collected from the trial sections, Figure 16 presents the density and stiffness data obtained at $20{ }^{\circ} \mathrm{C}$ for each core at the different kilometric points. As it can be observed, densities and stiffnesses obtained in the different sections offer a similar magnitude order and dispersion, which demonstrates that the mixtures studied have no differences in laying and compaction. It is clear that the density values for all the mixtures were even slightly higher than those measured in the laboratory (marked by the red line, which indicates adequate compaction of the materials), whilst the CRMB-WMA showed similar density and stiffness values to those of the reference mixtures, which confirms the satisfactory performance of this mixture despite the lower manufacturing temperature.
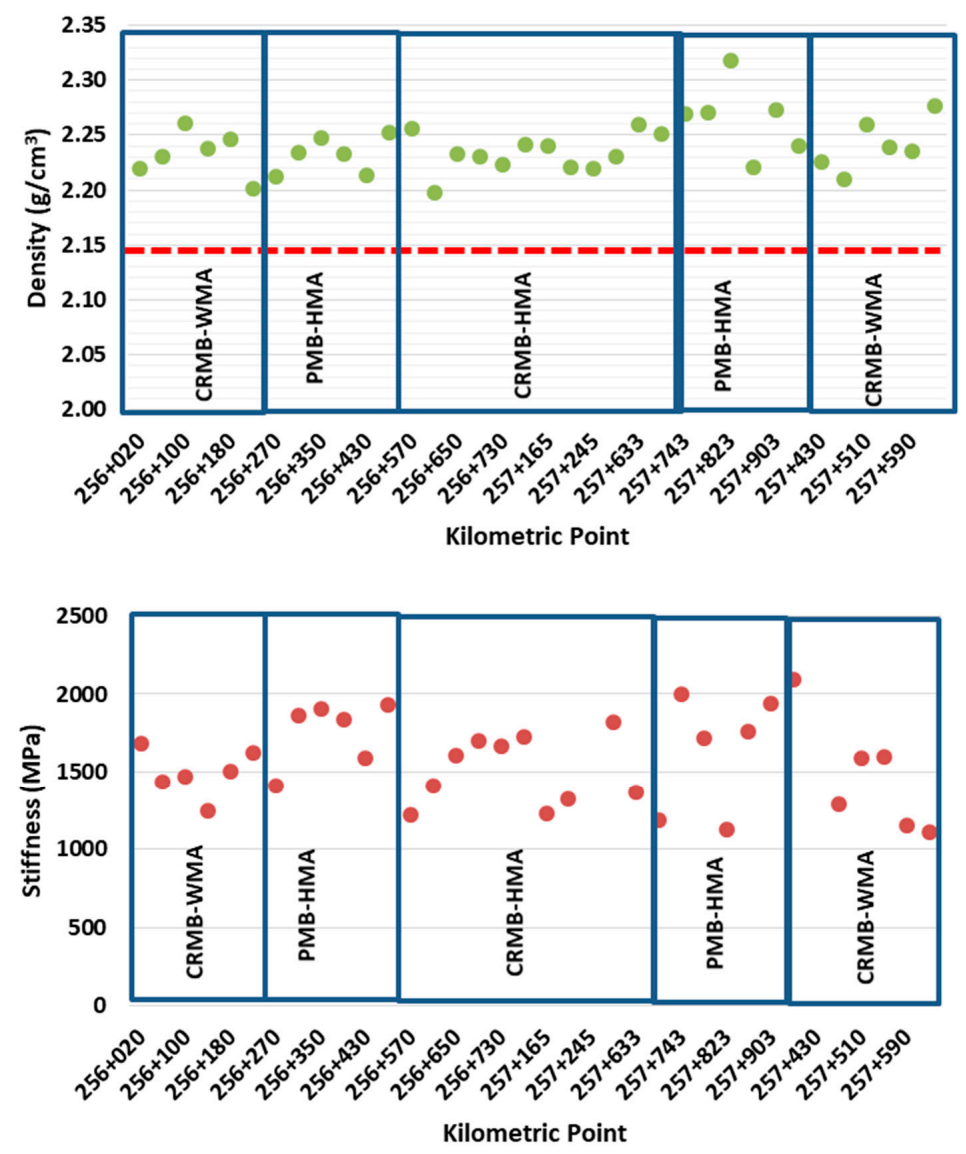

Figure 16. Results of density and stiffness $\left(20^{\circ} \mathrm{C}\right)$ for the cores obtained from different points of each trial section with the different mixtures analyzed. 
Figure 17 displays the average results of the failure cycle and Mean Damage Parameter measured by the UGR-FACT at $20^{\circ} \mathrm{C}$ for the various cores of each mixture. The graph shows that the fatigue life measured for the cores was slightly lower than that measured for the specimens manufactured in the laboratory, regardless of the type of mixture. Nonetheless, the results again show that all the mixtures presented comparable results, with the CRMB-WMA achieving an even longer fatigue life than the conventional HMA, thus providing evidence for the good response of this material in the long-term.

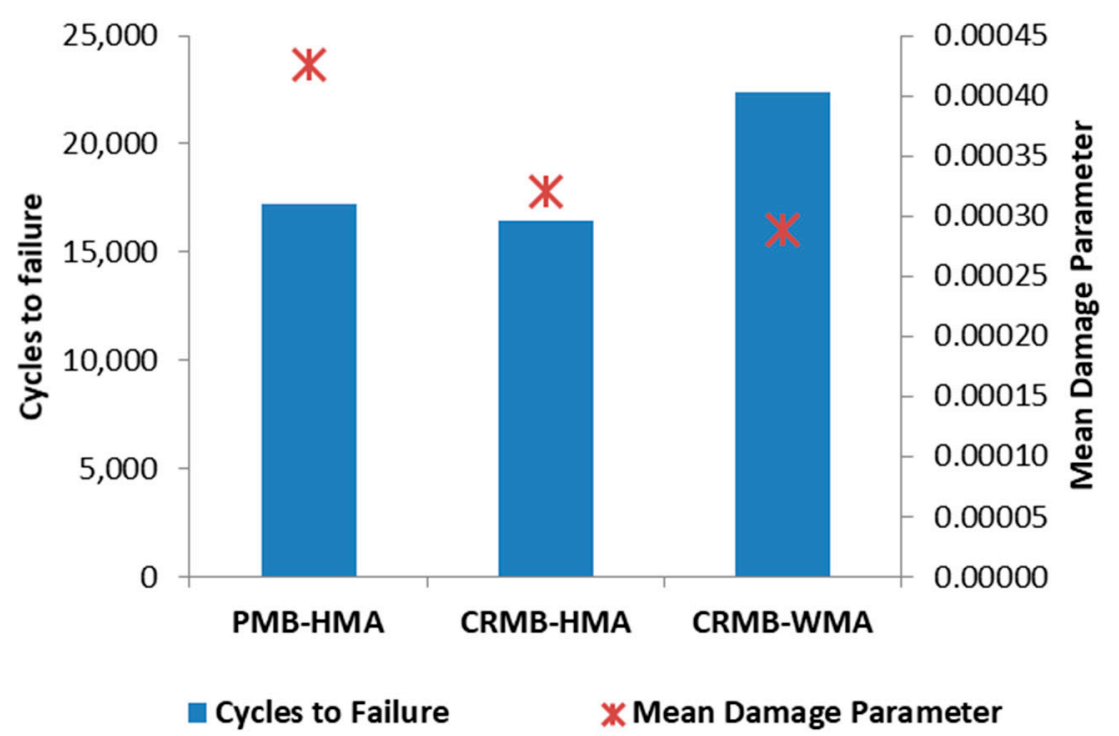

Figure 17. Results of UGR-FACT for the cores obtained from trial sections.

\section{Conclusions}

This paper presents the results obtained in a research project focused on developing sustainable high-performance asphalt mixtures manufactured at low temperatures with crumb rubber-modified bitumen to be used in the construction/rehabilitation of road pavements subjected to high traffic volumes and severe climate conditions. On the basis of the results obtained, the following conclusions can be drawn:

1. The laboratory study of the crumb rubber-modified bitumen and the mixture manufactured with it at $30^{\circ} \mathrm{C}$ lower than the hot conventional mixtures revealed a mechanical performance comparable to that recorded for traditional high-performance asphalt binders and hot mixtures in terms of elasticity, thermal susceptibility, workability, indirect tensile strength, water sensitivity, plastic deformations, and stiffness.

2. High-performance sustainable mixtures manufactured with crumb rubber-modified asphalt binders at $30^{\circ} \mathrm{C}$ lower than the hot conventional mixtures can be produced in conventional asphalt plants and spread and compacted with conventional equipment, achieving a material with a similar mechanical response to that of the reference hot mixtures (even higher in terms of resistance to fatigue and thermal cracking, particle loss, and permanent deformations) and a similar cost (the cost overrun associated with the use of additives can be partially compensated by the reduced energy consumption in-plant).

3. High-performance sustainable mixtures manufactured with crumb rubber-modified asphalt binders at $30{ }^{\circ} \mathrm{C}$ lower than the hot conventional mixtures can be transported long distances (one hour transport) without having workability or compaction problems.

4. Taken together, these findings suggest that sustainable high-performance mixtures presented in this paper could offer an interesting alternative to conventional hot mixtures for improving the durability of road pavements while reducing the environmental impacts associated with their construction/rehabilitation. 
Author Contributions: Conceptualization, F.M.-N., M.C.R.-G. and F.J.S.; methodology, F.M.-N. and M.C.R.-G.; validation, M.C.R.-G., E.E. and F.J.S.; formal analysis, F.M.-N., M.S.-S. and F.J.S.; investigation, F.M.-N., F.J.S., M.S.-S., M.C. and M.C.R.-G.; resources, M.C. and E.E.; data curation, F.M.-N., F.J.S. and M.S.-S.; writing-original draft preparation, F.M.-N., F.J.S. and M.S.-S.; writing-review and editing, M.C.R.-G., E.E., M.C.; supervision, M.C.R.-G.; project administration, M.C.R.-G., E.E.; funding acquisition, E.E. and M.C. All authors have read and agreed to the published version of the manuscript.

Funding: This research received no external funding.

Conflicts of Interest: The authors declare no conflict of interest.

\section{References}

1. Abtahi, S.M.; Sheikhzadeh, M.; Hejazi, S.M. Fiber-reinforced asphalt-concrete-A review. Constr. Build. Mater. 2010, 24, 871-877. [CrossRef]

2. Chomicz-Kowalska, A.; Gardziejczyk, W.; Iwa'nski, M. Moisture resistance and compactibility of asphalt concrete produced in half-warm mix asphalt technology with foamed bitumen. Constr. Build. Mater. 2016, 126, 108-118. [CrossRef]

3. Sol-Sánchez, M.; Moreno-Navarro, F.; García-Travé, G.; Rubio-Gámez, M.C. Analysing industrial manufacturing in-plant and in-service performance of asphalt mixtures cleaner technologies. J. Clean. Prod. 2016, 121, 56-63. [CrossRef]

4. Pouranian, M.R.; Shishehbor, M. Sustainability Assessment of Green Asphalt Mixtures: A Review. Environments 2019, 6, 73. [CrossRef]

5. Xu, O.; Xiao, F.; Han, S.; Amirkhanian, S.N.; Wang, Z. High temperature rheological properties of crumb rubber modified asphalt binders with various modifiers. Constr. Build. Mater. 2016, 112, 49-58. [CrossRef]

6. Moreno-Navarro, F.; Rubio-Gámez, M.C.; Jiménez del Barco, A. Tire crumb rubber effect on hot bituminous mixtures fatigue cracking behaviour. J. Civ. Eng. Manag. 2015, 22, 65-72. [CrossRef]

7. Moreno-Navarro, F.; Sol-Sánchez, M.; Jiménez del Barco, A.; Rubio-Gámez, M.C. Analysis of the influence of binder properties on the mechanical response of bituminous mixtures. Int. J. Pavement Eng. 2017, 18, 73-82. [CrossRef]

8. Kök, B.V.; Çolak, H. Laboratory comparison of the crumb-rubber and SBS modified bitumen and hot mix asphalt. Constr. Build. Mater. 2011, 25, 3204-3212. [CrossRef]

9. Nejad, F.M.; Aghajani, P.; Modarres, A.; Firoozifar, H. Investigating the properties of crumb rubber modified bitumen using classic and SHRP testing methods. Constr. Build. Mater. 2012, 26, 481-489. [CrossRef]

10. Huang, M.; Liu, J.; Zhang, X.; Li, D. Laboratory assessment of workability of asphalt rubber hot mixes using warm mix technology. Appl. Mech. Mater. 2012, 193-194, 452-457. [CrossRef]

11. D'Angelo, J.; Harm, E.; Bartoszek, J.; Baumgardner, G.; Corrigan, M.; Cowsert, J.; Harman, T.; Jamshidi, M.; Jones, W.; Newcomb, D.; et al. Warm-Mix Asphalt: European Practice; Report No. FHWA-PL-08-007; Federal Highway Administration, U.S. Department of Transportation: Alexandria, VA, USA, 2008.

12. Pouranian, M.R.; Notani, M.A.; Tabesh, M.T.; Nazeri, B.; Shishehbor, M. Rheological and environmental characteristics of crumb rubber asphalt binders containing non-foaming warm mix asphalt additives. Constr. Build. Mater. 2020, 238, 117707. [CrossRef]

13. Rubio, M.C.; Martínez, G.; Baena, L.; Moreno, F. Warm mix asphalt: An over-view. J. Clean. Prod. 2012, 24, 76-84. [CrossRef]

14. UNE-EN 13108-2. Bituminous Mixtures-Material Specifications-Part 2: Asphalt Concrete for very Thin Layers; AENOR, Asociación Española de Normalización y Certificación: Madrid, Spain, 2007.

15. PG-3. Pliego de Prescripciones Técnicas Generales para Obras de Carreteras y Puentes. Orden FOM/2523/2014; Ministerio de Fomento: Madrid, Spain, 2014.

16. EN 1426. Bitumen and Bituminous Binders-Determination of Needly Penetration; AENOR, Asociación Española de Normalización y Certificación: Madrid, Spain, 2015.

17. EN 1427. Bitumen and Bituminous Binders—Determination of the Softening Point_Ring and Ball Method; AENOR, Asociación Española de Normalización y Certificación: Madrid, Spain, 2015.

18. EN 13398. Bitumen and bituminous binders, Determination of the elastic recovery of modified bitumen; AENOR, Asociación Española de Normalización y Certificación: Madrid, Spain, 2010. 
19. EN 12697-12. Bituminous mixtures. In Test Methods for Hot Mix Asphalt_Part 12: Determination of the Water Sensitivity of Bituminous Specimens; AENOR, Asociación Española de Normalización y Certificación: Madrid, Spain, 2009.

20. EN 12697-22. Bituminous mixtures. In Test Methods for Hot Mix Asphalt_Part 22: Wheel Tracking; AENOR, Asociación Española de Normalización y Certificación: Madrid, Spain, 2008.

21. EN 12697-6. Bituminous mixtures. In Test Methods for Hot Mix Asphalt_Part 6: Determination of Bulk Density of Bituminous Specimens; AENOR, Asociación Española de Normalización y Certificación: Madrid, Spain, 2012.

22. EN 12697-8. Bituminous mixtures. In Test Methods for Hot Mix Asphalt_Part 8: Determination of Void Characteristics of Bituminous Specimens; AENOR, Asociación Española de Normalización y Certificación: Madrid, Spain, 2003.

23. EN 12697-26. Bituminous mixtures. In Test Methods for Hot Mix Asphalt_Part 26: Stiffness; AENOR, Asociación Española de Normalización y Certificación: Madrid, Spain, 2012.

24. EN 12697-17. Bituminous mixtures. In Test Methods for Hot Mix Asphalt-Part 17: Particle Loss of Porous Asphalt Specimen; AENOR, Asociación Española de Normalización y Certificación: Madrid, Spain, 2007.

25. EN 12697-46. Bituminous mixtures. In Test Methods for Hot Mix Asphalt_Part 46: Low Temperatura Cracking and Properties by Uniaxial Tests; AENOR, Asociación Española de Normalización y Certificación: Madrid, Spain, 2013.

26. Moreno-Navarro, F.; Rubio-Gámez, M.C. A review of fatigue damage in bituminous mixtures: Understanding the phenomenon from a new perspective. Constr. Build. Mater. 2016, 113, 927-938. [CrossRef]

27. Moreno-Navarro, F.; Sol-Sánchez, M.; Rubio-Gámez, M.C. (c) Exploring the recovery of fatigue damage in bituminous mixtures: The role of healing. Road Mater. Pavement Des. 2015, 16 (Suppl. 1), 75-89. [CrossRef]

28. Moreno-Navarro, F.; Rubio-Gámez, M.C. Mean damage parameter for the characterization of fatigue cracking behavior in bituminous mixes. Mater. Des. 2014, 54, 748-754. [CrossRef]

Publisher's Note: MDPI stays neutral with regard to jurisdictional claims in published maps and institutional affiliations.

(C) 2020 by the authors. Licensee MDPI, Basel, Switzerland. This article is an open access article distributed under the terms and conditions of the Creative Commons Attribution (CC BY) license (http://creativecommons.org/licenses/by/4.0/). 